VI.

\title{
Bericht aus Prof. Habermann's Klinik für Ohren-, Nasen- und Kehlkopfkranke an der Universität in Graz vom 1. October 1894 bis 31. December 1895.
}

\author{
Ton \\ Dr. med. 0tto Barnick, \\ klin. Assistent.
}

(Mit 2 Abbildungen and einer Curre.)

Der zweite Bericht uber die Thätigkeit unserer Klinik umfasst die Zeit vom 1. October 1894 bis zum 31. December 1895. Wir haben deswegen diesen Abschluss gewählt, um die regelmässig für dieses Archiv in Aussicht genommenen Berichte von nun an mit dem laufenden Kalenderjahre in Einklang zu bringen.

Einschliesslich der am 1. October $1894 \mathrm{im}$ Stande der Klinik verbliebenen 6 Patienten wurden bis zum Schluss dieses Jahres 25 Kranke stationär verpflegt, 14 Männer und 11 Weiber. Von diesen wurden 13 geheilt, 6 gebessert in ihre Heimath entlassen, ein Patient ging an Meningitis cerebrospinalis zu Grunde, (Arch. 38, pag. 203, Fall 32) und 5 Kranke bedurften noch einer weiteren klinischen Pflege. Während dieser Zeit wurden 469 Patienten ambulatorisch behandelt, wobei die aus dem vertlossenen Berichtsjahre verbliebenen nicht miteingerechnet sind. - Im Jahre 1895 nahmen 2497 Kranke unsere Hilfe in Anspruch. Von diesen wurden 113 in die Klinik aufgenommen, 57 Männer und 56 Weiber. Eine vollständige Hellung wurde bei 66 Kranken erzielt, 42 wurden ambulatorisch weiter behandelt, und 2 blieben ungeheilt. (Taubheit nach Meningit. cerebrosp. epid.) Ein Kind und ein Mann starben infolge einer acuten Miliartuberculose, und eine ältere Frau erlag einer Pneumonie. Von den 42 als gebessert Entlassenen erlangten bis zum 1. Januar 1896 noch 31 Kranke ihre volle Gesundheit wieder, 6 verblieben im Stande der Klinik.

Die Zahl der Studenten, welche die klinischen Vorlesungen 
über Pathologie und Therapie der Krankheiten des Gehörorganes, beziehungsweise der Nase and des Kehlkopfes besuchten, betrug im Wintersemester $1894 / 95.20$, resp. 15, im folgenden Sommersemester je 8 und im Wintersemester 1895/96. 37, resp. 22.

Als klinischer Assistent war Dr. Barnick thätig. Ausserdem standen freiwillig im Dienste der Anstalt die Herren Dr. Ern s t Richter (v. 1. October 1894 bis 30. September 1895), Dr. Karl Biehl (v. 1. Octbr. 1894 bis 31. Dezbr. 1895) und Dr. Richard Freitag (v. 1. October 1895 bis 30. März 1896).

Aus der Klinik wurden während dieser Zeit folgende wissenschaftliche Arbeiten veröffentlicht:

1. Habermann: Beiträge zur Kenntniss der chronischen Laryngitis mit Pachydermie. (Zeitschr. f. Heilk. B. XVI. 1895.)

2. Richter: Die nicht perforirende eitrige Entzïndung der Stirnhöhlen und ihre operative Behandlung. (Inangural-Dissertation, Leipzig 1895.)

3. Biehl: $\mathrm{Zur}$ Pathologie der "blutenden Septumpolypen." (Monatsschr. f. Ohrenheilk. 1895. Nr. 6.)

Die Verhältnisse des Alters und Geschlechtes, sowie die Zahl der einzelnen Erkrankungsformen und Operationen ergeben sich aus folgenden Tabellen:

I. Alterstabelle.

\begin{tabular}{|c|c|c|c|c|c|c|c|c|c|c|}
\hline \multirow{2}{*}{ Jahre } & \multicolumn{2}{|c|}{$\begin{array}{l}\text { IV. Quartal } \\
1894\end{array}$} & \multicolumn{2}{|c|}{$\begin{array}{l}\text { I. Quartal } \\
1895\end{array}$} & \multicolumn{2}{|c|}{$\begin{array}{l}\text { II. Quartal } \\
1895\end{array}$} & \multicolumn{2}{|c|}{$\begin{array}{l}\text { III. Quartal } \\
1895\end{array}$} & \multicolumn{2}{|c|}{$\begin{array}{c}\text { IV. Quartal } \\
1895\end{array}$} \\
\hline & 崖 & $\begin{array}{l}\frac{5}{0} \\
\frac{0}{0}\end{array}$ & 莺 & 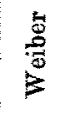 & 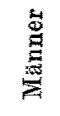 & $\begin{array}{l}\stackrel{\overrightarrow{0}}{0} \\
\overrightarrow{0}\end{array}$ & 总 & $\frac{5}{30}$ & 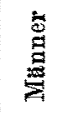 & $\stackrel{5}{\frac{5}{*}}$ \\
\hline $0-2$ & 1 & 2 & - & 1 & 8 & 6 & 4 & 3 & 3 & 6 \\
\hline $3-10$ & 24 & 27 & 23 & 18 & 38 & 49 & 27 & 37 & 37 & 37 \\
\hline $11-20$ & 61 & 60 & 67 & 59 & 68 & 54 & 76 & 76 & 76 & 91 \\
\hline $21-30$ & 66 & 44 & 96 & 82 & 84 & 74 & 89 & 82 & 78 & 80 \\
\hline $31-40$ & 35 & 35 & 43 & 37 & 67 & 46 & 75 & 54 & 39 & 50 \\
\hline $41-50$ & 36 & 29 & 40 & 31 & 46 & 30 & 35 & 34 & 22 & 25 \\
\hline $51-60$ & 12 & 11 & 21 & 21 & 25 & 15 & 30 & 28 & 27 & 13 \\
\hline $61-70$ & 9 & 5 & 8 & 11 & 16 & 10 & 16 & 3 & 8 & 7 \\
\hline $71-80$ & 9 & 2 & 3 & 4 & 5 & 4 & 9 & $\mathrm{t}$ & 2 & 5 \\
\hline $81-90$ & i & - & 1 & - & - & - & - & - & 1 & - \\
\hline $91-100$ & - & 一 & - & - & - & - & - & - & - & - \\
\hline \multirow{2}{*}{$\begin{array}{l}\text { Vierteljahrs- } \\
\text { summe }\end{array}$} & 254 & 215 & 302 & 264 & 357 & 288 & 361 & 318 & 293 & 314 \\
\hline & \multicolumn{2}{|c|}{469} & \multicolumn{2}{|c|}{566} & \multicolumn{2}{|c|}{645} & \multicolumn{2}{|c|}{679} & \multicolumn{2}{|c|}{607} \\
\hline 1895 & \multicolumn{2}{|c|}{-} & \multicolumn{8}{|c|}{2497} \\
\hline Im Ganzen & & & & & & 66 & & & & \\
\hline
\end{tabular}


II. Krankheilstabelle.

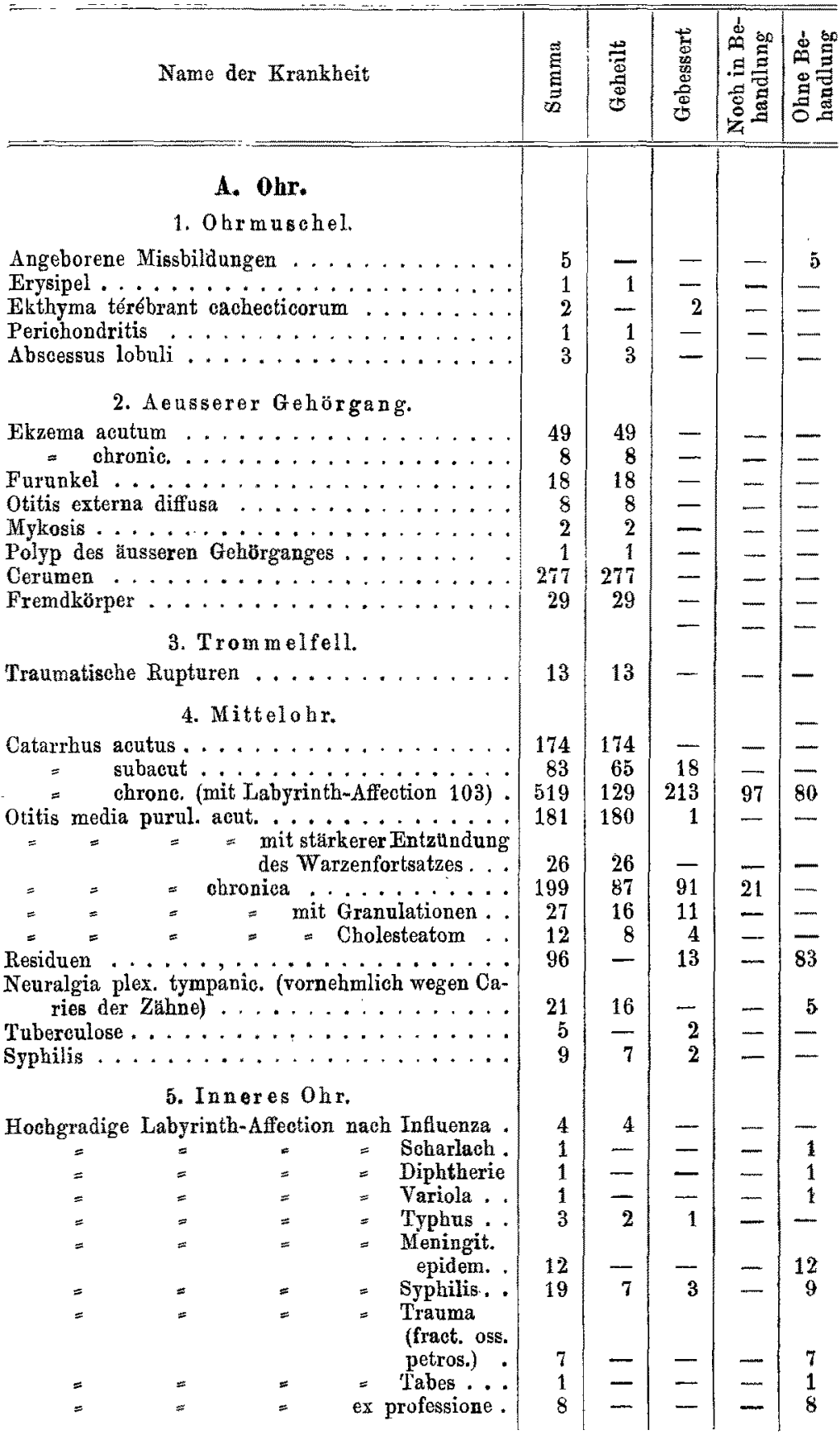




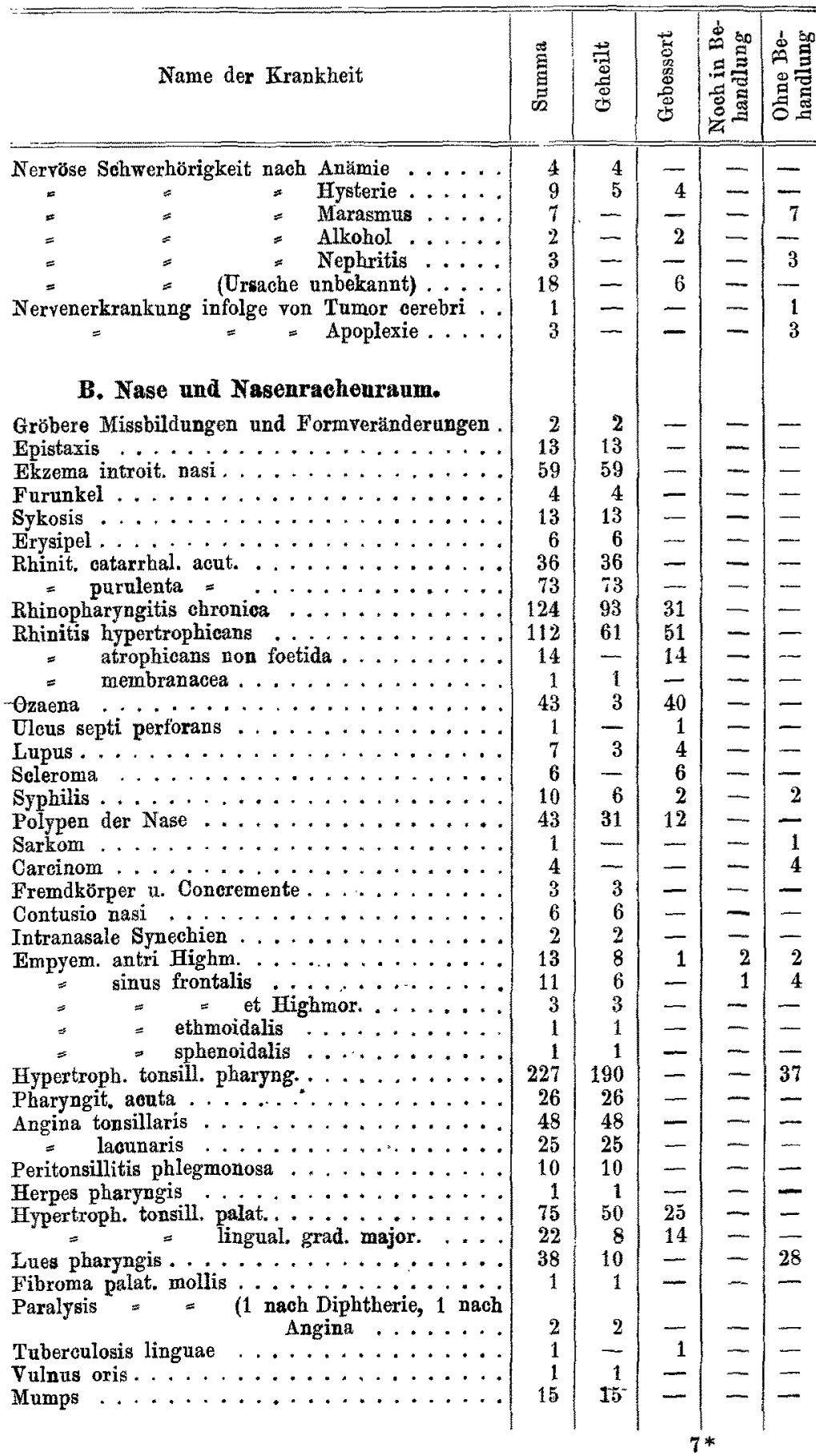




\begin{tabular}{|c|c|c|c|c|c|}
\hline Name der Krankheit & 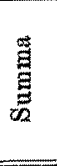 & 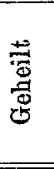 & 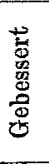 & 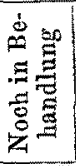 & 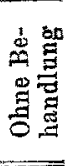 \\
\hline C. Kehlkopf. & & & & & \\
\hline Laryngitis aouta $\ldots \ldots \ldots \ldots \ldots$ & 38 & 38 & - & - & - \\
\hline$=\quad$ cum pares. musc. thyr aryt. int. & 24 & 24 & - & - & 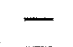 \\
\hline$=\ldots=\Rightarrow \quad=\quad$ transyers. $\ldots$ & 7 & 7 & - & - & - \\
\hline Laryngitis chronica & 16 & 9 & 7 & - & - \\
\hline$=\quad=$ mit Pachydermie... & b & 2 & 4 & - & \\
\hline Neuropathische Läbmungen (Struma) & 1 & - & - & - & \\
\hline Tubereulosis laryngis $\ldots \ldots \ldots \ldots \ldots$ & 26 & 3 & 23 & - & $m$ \\
\hline Syphilis $\quad=\ldots \ldots \ldots \ldots$ & 26 & 26 & - & - & - \\
\hline$\ldots \ldots \ldots$ & 5 & 3 & - & - & \\
\hline Chondro-Sareoma laryngis & 1 & - & 一 & - & \\
\hline$\ldots \ldots \ldots$ & 1 & - & - & - & 1 \\
\hline Tracheal-Stenose durch Struma....... & 38 & - & 14 & - & 24 \\
\hline
\end{tabular}

\section{Operationstabelle.}

\begin{tabular}{|c|c|c|c|c|c|}
\hline Name der Operation & $\stackrel{\vec{E}}{E}$ & 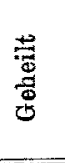 & 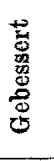 & 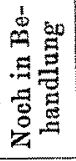 & 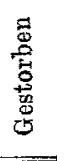 \\
\hline Operation an der Ohrmuschel .......... & 1 & 1 & - & - & - \\
\hline Incision des Gehörganges. . . . . . . . . & 15 & 15 & - & 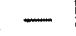 & - \\
\hline Entfernung von Fremakörpern aus dem $0 \mathrm{hr}$.. & 5 & 5 & - & - & - \\
\hline Extration ron Ohrpolypen $\ldots \ldots \ldots \ldots$ & 47 & 23 & 24 & - & - \\
\hline $\begin{array}{l}\text { Paraecntese des Trommelfelles } \ldots \ldots \ldots \ldots \\
\text { Tinfache Aufmeisselung des Proc. mast. nach }\end{array}$ & 101 & 101 & - & - & - \\
\hline 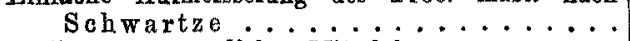 & 18 & 14 & - & - & $\left.2^{1}\right)$ \\
\hline Freilegung sämmtlicher Mittelohrränme... & 20 & 15 & 2 & - & 2 \\
\hline Entfernung von Fremdkörpern aus der Nase & 2 & 2 & - & - & - \\
\hline $\begin{array}{l}\text { Abtragung kleinerer Muschel-Hypertrophien } \\
\quad=\quad \text { der hypertr, hinteren unteren Muschel- } \\
\text { enden }\end{array}$ & 49 & 49 & - & - & - \\
\hline Extraction von Nasenpolypen $\ldots \ldots \ldots$ & 31 & 31 & - & - & 二 \\
\hline$=\quad=$ Choanalpolypen & 2 & 2 & - & - & - \\
\hline Abscessspaltung an der Nasenscheidewand & 1 & 1 & - & - & - \\
\hline Eröffnung der Kieferhöhle & 11 & 8 & 1 & 2 & - \\
\hline Entfernung eines Sequesters aus dem Oberkiefer. & 1 & 1 & - & - & - \\
\hline Eröffnung der Stïrnhöhle $\ldots \ldots \ldots \ldots$ & 7 & 6 & - & $\mathfrak{l}$ & - \\
\hline Entfernung der Rachenmandel . . & 190 & 190 & - & - & 一 \\
\hline & 50 & 50 & - & - & - \\
\hline Spaltung phlegmonöser Abscesse der Mundhöhl & 8 & 8 & - & - & - \\
\hline Entferuang von Larynxpolypen $\ldots \ldots$. & 3 & 3 & - & - & - \\
\hline
\end{tabular}

Im Frühjahr 1895 kamen an der hiesigen Klinik zwei Fälle von theilweiser Nekrose der Ohrmuschel zur Beobachtung, deren klinischer Verlauf nicht uninteressant erscheint. Diese regressive Ernährungsstörung boten $\mathrm{zwoi}$ sebr herabgekommene, scrophulöse

1) 2 :Kranke wurden später radical operirt. 
Patienten im Alter von 3 und 4 Jahren dar, die kurze Zeit darauf an den Folgen einer chronischen Knochen- und Lymphdrüsentuberculose zu Grunde gingen. In jedem einzelnen Falle trat die Erkrankung an der Vorderfläche des Helix auf und erstreckte sich von hier ans weiter um sich greifend bis zur behaarten Kopfhaut.

Unter heftigem Juckreiz zeigten sich zuerst kleine, runde Papeln von lebhaft rother Farbe, die sich in kurzer Zeit zu fünfpfennigstückgrossen Scheiben vergrösserten, während der centrale Theil derselben sich abplattete und mit einer schwarzen Kruste bedeckte. Diese fiel nach wenigen Tagen ab, und es kam eine kleine ulcerirende, mit blutigem Eiter belegte Mulde zum Vorschein, die sich allmählich immer mebr vergrösserte. Um dieses Geschwür herum erschienen neue, welche ineinander übergriffen und nach und nach eine ausgedehnte Geschwïrsfläche bildeten.

Da die Befunde bei beiden Patienten ungefähr dieselben waren, so sei es gestattet, nur auf die auch bildlich dargestellten pathologischen Veränderungen des einen Falles etwas näher einzugehen.

Der Helix ist in seinem oberen Abschnitt fast vollständig zerstört. Ein Theil seines häutigen Ueberzuges hat sich vom Knorpel losgelöst und als Falte nach unten umgeschlagen. Hebt man diese empor, so bemerkt man, dass beide Crura furcata, sowie die Fossa intercruralis in eine einzige grosse Geschwürsfläche umgewandelt sind, die sich nach hinten und oben zu auch auf den Anthelix und die Fossa scaphoidea fortsetzt. Im oberen Theile dieses Geschwüres ist der Knorpel gänzlich zum Schwund gebracht, im unteren, welcher sich gegen das gesunde Gewebe zu in zwei halbmondförmigen Ausbiegungen absetzt, ist derselbe noch erhalten und schimmert hie und da durch den sehmutzigbraunen Belag weiss durch. Nur eine ungefähr $2 \mathrm{Mm}$. grosse Stelle zeigt eine gänzliche Zerstörung aller Weichtheile, so dass man mit einer Sonde leicht zur Rüekseite der Ohrmuschel gelangen kann. Dicht unterhalb des oberen, aúsgedehnten Geschwiures befinden sich drei kleinere, erst kurz vor dem Tode der Kranken entstandene Substanzverluste, die nur bis zur Knorpelhaut vorgedrungen sind. Ihre Ränder sind scharf, wie mit dem Łocheisea ansgestossen, ihr Grund ist eitrig belegt. Die Rückfhacheder Q'k muschel, sowie die im Umkreis von ungefähr 5 . W. ho benachbarte Kopf haut bilden eine einzige ausgebreitete, u ar freadéläche.

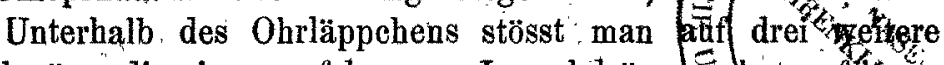
Geschwüre, die einem apfelgrossen Lymphdrüsenwäket sufsitzen. 
Ihre von bläulichrother Haut gebildeten Ränder sind unregelmässig gezackt, sehlaff und tiberhängend. Ihr tiefliegender Grund entleert einen dünnflüssigen, mit käsigen Brocken untermischten Eiter, in welchem einzelne Tuberkelbacillen aufgefunden werden. Die histologische Untersuchnng dieser Geschwüre ergab ein subentanes, gummatöses Scrophuloderma, welches verkästen Lymphdrüsen unmittelbar aufsass.

Fig. 1.

Ganz unabhängig von dieser secundären Hauttuberculose entwickelten sich die pathologischen Veränderungen an der Ohrmuschel. Klinisch und histologisch stimmt der Process mit einer Erkrankungsform überein, die von den Franzosen als Ekthyma térébrant de l'enfance ${ }^{1}$ ) bezeichnet wird und bisher nur an der behaarten Kopfhaut, den Bauchdecken und den Leistenfalten zur

1) Ekthyma terébrant de l'enfance. Recherches bacteriologiques. Par G. Baudouin et Lonis Wickham. Annales de Dermatologie et de Siphillgraphie. Tome IX. 1888. p. 805-812. 
Beobachtung kam. Wahrscheinlich werden hierbei durch den kratzenden Nagel die auf der Haut liegenden Eiterkokken in die Hornschicht übergeimpft. In unseren Fällen handelte es sich um ein sogenanntes hämorrhagisches Ekthyma. An den Rändern der Geschwüre wurden zahlreiche Blutungen in die Oberhaut, sowie eine Endarteriitis der Cutisgefässe nachgewiesen. Der Grund der Geschwüre zeigte iiberall eine wenn auch nur wenig entwickelte Granulationsbildung. Im Deckglaspräparat, sowie in den nach Weigert gefärbten Schnitten fanden sich Staphylokokken mit Streptokokken untermischt vor.

Während des verflossenen Zeitabschnittes wurden 18 einfache Aufmeisselungen des Warzenfortsatzes vorgenommen, und in 20 Fällen wurde die Freilegung sämmtlicher Mittelohrräume ausgeführt.

Von den 18 nach Schwartze operirten Patienten wurden 14 geheilt. Eine ältere Frau starb infolge einer intercurrenten Pneumonie, and ein Kind ging an einer Scharlachnephritis zu Grunde. Bei 2 Kranken musste wegen Fortschreitens des Entzündungsprocesses im Knochen die Radicaloperation angeschlossen werden. In 3 Fällen waren die Weichtheile über dem Zitzenfortsatze unverändert, bei 6 Patienten war es zu einem Oedem und einer stärkeren Infiltration des äusseren Hautüberzuges gekommen, und 9 mal wurde eine grössere subperiostale Eiteransammlung festgestellt, die sich bei 7 Kranken zu einem fistulösen Durchbruche der Corticalis hinzugesellt hatte und in einem Falle von einem tiefen Senkungsabscess längs der grossen Halsgefässe begleitet war. Von 5 Sequestern des Warzenfortsatzes gehörten zwei der medianen Antrumwand an und enthielten Theile des horizontalen Bogenganges. Bei 5 Kranken war das entzündliche Granulationsgewebe nach theilweiser Zerstörung des Sulcus bis zur häutigen Wand des grossen Hirnquerblutleiters vorgedrungen. Nur bei einer Patientin führte dieser Process zu einer Phlebitis des Sinus sigmoideus und der Vena jugularis interna mit folgender metastasirender Pyämie. Diese Krankengeschichte bietet so viel Interessantes dar, dass es sich wohl verlohnt, sie einer etwas eingehenderen Betrachtung zu unterziehen.

Juliana Pf., 52 Jahre alt, Taglöhnersfrau aus Kirchberg.

Phlebitis sinus sigmoid. et venae jugular. dextr. post otitid. med. supp. acut. Pyämia.

Patientin erkrankte Anfang December 1894 an Mumps. Unterhalb und vor dem rechten 0 hr war sie stark geschwollen, sie hatte heftige Schmerzen besonders beim Kauen und konnte den Mund kaum öffnen. Auf warme Umschläge ging zwar die Schwellung innerhalb 8 Tagen zurück, dafür traten aber hef- 
tige Schmerzen im rechten Ohre auf, Sausen, Rauschen, zunehmende Schwerhörigkeit. Hierzu gesellten sich starke rechtsseitige Kopfschmerzen, so dass die Kranke während 3 Wochen keinen Schlaf finden konnte. Endlich trat Neujabr 1895 ein eitriger Ausfluss aus dem rechten Ohre auf, die Schmerzen liessen nach. Einige Tage später bekam die Kranke infolge einer Verkühlung abermals heftige Schmerzen in dem anhaltend secernirenden Ohre verbunden mit starkem Schwindel und Uebelsein. Die Patientin erbrach mehrere Tage hindurch und wurde ron wahnsinnigen Kopfschmerzen gefoltert. Am 15. Januar traten auch Schmerzen am Warzenfortsatz und der rechten seitlichen Halsgegend auf. Dabei hatte die Kranke Fieber bis $39,5^{\circ}$, Puls 88 , ofters hefṫges Frösteln mit darauffolgendem starken Hitzegefühl. Seit 17. Januar Scbmerzen im Nacken bei Bewegungen, drei Tage später Kreuzschmerzen und heftige Beschwerden uber dem linken Hand- und Hüftgelenk. Zu dieser Zeit bestand Diarrhoe, kein Appetit, viel Durst. Früher war Patientin nie obrenkrank. Vor 7 Jahren wurde ihr der linke Unterschenkel wegen einer complicirten Fractur amputirt. Die Kranke bat dreimal geboren, zwei Kinder starben gleich nach der Geburt. Im Uebrigen war Patientin stets gesund. Am 21. Januar 1895 lässt sich die Patientin, die erst seit 8 Tagen zu Bette lag, in das allgemeine landschaftliche Krankenhans zo Graz aufnehmen und wird auf die I. medic. Abtheilung gelegt. Hier wurde bei ihrem Eintritt Fieber mit Herpes labialis festgestellt. In der Gegend des rechten Warzenfortsatzes bestand Oedem der Weichtheile mit Druckempfindlichkeit des Knochens. Ebenso war das linke Handgelenk bei Berührung sehr schmerzhaft.

Am 23. Januar 1595 wurde die Kranke von Herrn Prof. Habermann untersucht. Es fand -sich damals eine mässige Druckempfindlichkeit längs der Vena jugularis vor. Das rechte Trommelfell war mässig geschwollen und vorgebaucht, im vorderen unteren Quadranten befand sich eine kleine Perforation mit pulsirendem Lichtrefiex. Die Untersuchung der Angen ergab beiderseits gleich weite Pupillen, Neuritis optica, links deutlicher ausgeprägt. Auf der Papille des linken Opticus innen unten bereits Exsudation. Auf Grund dieses Befundes wurde die Diagnose einer Sinusthrombose gestellt, die Kranke auf die grosse Lebensgefahr, in welcher sie schwebte, aufmerksam gemacht und ihr eine Trepanation des Wagenfortsatzes dringend angerathen, die sie jedoch entschieden ablehnte.

Am 24. Januar wurde die Patientin auf die medicinische Klinik transferirt. Ihr Sensorium war damals etwas benommen, die Bewegungen der Bulbi sind nach allen Richtungen frei, es findet sich keine Storrung der äbrigen Hirnnerven. Die Kopfbewegungen sind schmerzhaft, besonders nach der rechten Seite bin, Nackensteife nur unbedeutend. 'Die Gegend des rechten Warzenfortsatzes ist geschwollen, zwischen Kopfnicker und Kieferwinkel grosse Schmerzhaftigkeit. Die Jugularis kann nicht als Strang durchgetastet werden. Am Herzen sind keine pathologischen Veränderungen nachzuweisen. Die Untersuchung der Lungen ergicbt nirgends eine Dämpfung; das Athemgeräusch ist vorn scharf vesiculär, hinten findet sich klein- und mittelblasiges Rasseln vor, kein Bronchialathmen. Die Milz ist vergrössert, nicht palpabel. Am linken Handrücken besteht eine Entzùndung articulärer und periarticulärer Weichtheile. Intermittirendes Fieber.

26. Januar: Der Harn enthält Nucleoalbumin, Albumin und Pepton. Im Sediment finden sich reichlich rothe Blutkörperchen vor, einzelne $\mathrm{zu}$ Cylindern angeordnet; granulirte und Epithelcylinder in geringer Zahl. Fieber stark remittirend, Cerebralsymptome unverändert. Andeutung von Nystagmus. Fluctuirender Abscess am linken Ulnarköpfehen. Die mikroskopische und culturelle Untersnchung des Abscessinhaltes ergicbt das Vorbandensein von Streptokokken. Sputa schleimig-bämorrhagisch. Starke Leukocytose.

1. Februar. Fieber von demselben Typus. Spnta nicht mehr hämorrhagisch. Geringe Albuminurie. Im Sediment viel Blut, einige hyaline und granulirte Cylinder mit Plattenepithelien untermischt. - Das Ohr zeigt seit 25. Januar keine Secretion mehr.

7. Februar. Die Kranke willigt endlich in eine Operation ein und wird anf die Ohrenklinik verlegt. Sie bot folgenden Befund dar: 


$$
\begin{aligned}
& \text { W. }{ }^{1} \\
& \text { R. }>L \text {. } \\
& \theta\left(\begin{array}{c}
u . \\
u s . \\
u w .
\end{array}\right)^{\frac{1}{\theta}} \\
& 0,05 \text { fl. } 020 \\
& 1,50 \text { st. } 6,0 \\
& \text { 5" cp. 6" } \\
& +9^{\prime \prime} R .+14^{\prime \prime} \\
& \text { - co. } \\
& -21^{\prime \prime} c^{4} \cdot-15^{\prime \prime} \\
& +C .+ \\
& 5,6,7,8.5,6,7,8 \text {; } \\
& +c .+
\end{aligned}
$$

R. Perforation geschlossen, Trommelfell etwas geröthet und mässig geschwollen, Warzenfortsatz bei Druck stark empfindlich. Vom Proc. mast. nach abwärts ist ein schmerzhafter, mässig derber Strang abzutasten.

$L$. Trommelfel! milchig getrübt, verdickt, flach.

Nase: schleimig eitriges Secret in reichlicher Menge. Hintere Rachenwand dünn, trocken, glänzend.

Augen: Neuritis optica beiderseits. In der linken Netzhaut frische Exsudate.

Milz: vicht paipabel.

8. Februar. Sinusoperation.

Typischer Hant-Periostschnitt. Starke Blutung aus den Knochengefässen und den reichlichen, mit stark verdickter Schleimbaut ausgekleideten Zellen des Warzenfortsatzes. Das Antrum wird eröffnet, in diesem kein Eiter. Freilegung des Sinus durch Fortmeisseln des Knochens nach hinten bis zu seiner oberen und unteren Umbiegung. Der Knochen erweist sich im Snlcus stark erweicht. Beim Wegnehmen des Knochenblattes an der oberen Umbiegung des Querblutleiters entleert sich aus einer feinen Oeffnung in demselben ein dünnes, gelblich eitriges Secret. Die Sinuswand ist, soweit sie freiliegt, im oberen. Theile von blänlicher, im unteren von mehr gelblicher Farbe. Einführen einer Hohlsonde durch die Fistel in den Sinus nach unten zu, die Wand des Sinus sigmoideus wird gespalten, es entleeren sich etwa zwei Esslöffel voll Eiter aus demselben, besonders wenn man auf die Geschwulst am Halse drückt. Bierauf wird mit der Scheere ein grosses, länglich ovales Loch aus der Sinuswand ausgeschnitten. Die hintere Wand des Sinus erscheint darunter gran, nicht wesentlich verändert.

Darauf wird dicht unter dem Unterkieferwinkel längs des vorderen Randes des Kopfnickers ein 5-6 Cm. langer Schnitt angelegt, um die Vena jugular. intern. aufzusuchen. Hierbei wird die Jugularis externa doppelt unterbunden, darchsehnitten und die vergrösserte Schilddrüse medianwärts gedrückt. Während man die Weichtheile in der Nähe der gemeinsamen Gefässscheide stumpf auseinanderdrängt, ergiesst sich von oben her reichlich dünnflüssiger Eiter. Nach dessen Abspülung sieht man das Gewebe in der Gegend der Jugul. int. morsch und grau verfärbt. Die Vena selbst ist trotz genauen Suchens hier nicht aufzufinden. Hierauf werden beide Wundflächen vorsichtig mit Sublimat 1:10000 abgéspült. und längs der Jugularis wird nach oben zu ein Drainrohr eingeführt. Im oberen Winkel der Halswunde eine Naht. Ein zweites Drain in die Sinuswunde hinter dem Ohr. Tamponade. Deckverband.

9. Februar. Patientin hat die Operation leidlich überstanden, Abfall des Fiebers auf subnormale Temperatur. Vor Mitternacht hat die Kranke ziemlich rubig geschlafen, nach Mitternacht obne Schlaf; eine längere Zeit hindurch ziemlich heftiger, kalter Schweiss. Heute früh ist ihr Befinden zufriedenstellend, kein Fieber, erst gegen Abend wieder langsame Steigerung bis anf $38,2^{\circ}$.

10. Februar. Patientin fühlt sich ziemlich wohl. Appetit gat, Verbandwechsel der Halswunde. Diese zeigt keine Entzündnngserscheinungen, die Eiterabsondernng? von oben her ist ziemlich stark. Abspülen mit Sublimat. - Spaltung des bereits stark fluctuirenden Abscesses hinter dem linken

1) $W_{.}=$Weber, $R .=$ Rinne (normale Perceptionsdauer $33^{\prime \prime}$ ), $u$. = Uhr in Luftleitung, us. $=$ Uhr an der Schläfe, uw. Uhr am Warzenfortsatz, $f l .=$ Flüsterstimme, $s t$. = Umgangssprache, $c p .=$ Lucae'sche Stimmgabel am Proc. mast. (normale Perceptionsdauer $13^{\prime \prime}$ ), co. = Lucae'sche Stimmgabel vor dem Obr (normale Perceptionsdauer $42^{\prime \prime}$ ), $c^{4} .=43^{\prime \prime}$ normale Perceptionsdauer, $C=$ tiefe Stimmgabel mit 64 Schwingungen in der Secunde. 
Trochanter major unter Aether-Spray. Es entleert sich über $200 \mathrm{Grm}$. Eiter. Die Wunde wird mit Sublimat abgespült, drainirt, Tamponade, Verband. Starke Leukocytose.

11. Februar. Subjectives Befinden ziemlich gut, Abends immer noch Temperatursteigerung über $39^{\circ}$. Die Schwellung über dem linken Hüftgelenk ist seit der gestrigen Abscessentleerung bedeutend zurückgegangen. Die Kranke klagt nirgends mehr tuber Schmerzen.

12. Februar. Verbandwechsel der Wunde am Warzenfortsatz. Mässige Secretion, Wunde reactionslos, ohne Entzündungserscheinungen. Auch die Sinuswand zeigt ein gutes, schon mehr bläulichrothes Aussehen. Abspülen mit Sublimat, Drainage, Verband.

13. Februar. Snbjectives Befinden zufriedenstellend, Appetit anhaltend gut. Seit heute Stechen in der rechten Brustseite und etwas Husten. Abendliche Temperatursteigerung bis $39,4^{\circ}$.

14. Februar. Alle 3 Wunden, deren Verband täglich erneuert wird, zeigen einen normalen Heilverlauf. Die Secretion aus denselben ist gering. Das obere Drainrohr im Sinus wird heute fortgelassen. Schon seit gestern haben sich bei der Kranken Schmerzen über der rechten Hüfte eingestellt. Ueber dem Os ilei dieser Seite befindet sich eine diffuse Schwellung von Handtellergrösse, welche anf Druck schmerzhaft erscheint. Höchste Abendtemperatur $38,8^{\circ}$.

19. Februar, Tăglicher Verbandwechsel. Nur geringe abendliche Temperatursteigerung. Heute klagt die Kranke aber Kreuzschmerzen, Abends 8 Uhr wieder $39,2^{\circ}$.

20. Februar. Da heute Abend das Fieber wieder auf $39,7^{\circ}$ gestiegen, wird sofort nochmals der Verband gewechselt. Die Patientin klagt über stärkeren Husten und Kopfschmerz. Die Untersuchung der Lungen ergiebt eine ausgebreitete Bronchitis, nirgends ist eine Dämpfung zu constatiren. Ipecac: Infus.

21. Februar. Die Stauungserscheinungen, welche früher am Sehnerveneintritte festgestellt wurden, scheinen etwas zurückzugehen, doch sind neben den alten Exsudatflocken im linken Auge zwei neue aufgetreten. Die linke Pupille ist weiter und reagirt etwas träger.

22. Februar. Die Wunden zeigen nur eine geringe Granulationsbildung und eine mässige Secretion. Thre Ränder zeigen nirgends einen grauen Belag. Trotzdem hält die hohe abendliche Temperatursteigerung fortwährend an.

24. Februar. Patientin klagt, dass sie viel schlechter höre. Gegen Abend hat die Kranke einmal erbrochen.

$$
\begin{gathered}
W . \\
R .<L . \\
0\left(\begin{array}{c}
u s \\
u w
\end{array}\right) \frac{1}{\infty} \\
f l . \\
0,20 \text { st. } \\
-31 " c^{4}-19^{\prime \prime} \\
+c++
\end{gathered}
$$

25. Februar. Früh beim Verbandwechsel wird der obere, in der Knochenwunde gelegene Theil des Sinus, welcher sich als bruchig und sehr morsch erweist, mit Sublin. 1:10000 ausgespult. Der untere Absehnitt, welcher durch Granulationen verlegt war, wird wieder eröffnet, sondirt und mittels eines ungefähr $2 \mathrm{Cm}$. langen Drains nach nuten $\mathrm{zu}$ offen erhalten. Hierbei entleert sich kein Eiter, nur wenige rothbraune Thrombusmassen werden sichtbar. Die Kranke ist heute etwas unbesinnlich, besonders gegen Abend. Auf Befragen giebt sie keine Antwort and erkennt den Arzt nicht. Kein Stuhlgang. In der Haut der Brust befinden sich mehrere kleine, bis stecknadelkopfgrosse Blutungen, die sich gegen Abend zu vermehren. Temperatur 6 Uhr Abends $40^{\circ}$. Nochmals Verbandwechsel.

26. Februar. Sensorium heate morgen frei, die Kranke nimmt etwas Speise zu sich, Augenbefund: Die Staungserscheinungen haben seit 21. Fe- 
bruar eher zugenommen, auch scheinen neue Exsudatflocken aufgetreten zu sein. Im linken Auge ist eine deutliche Netzhautblutung zu constatiren.

27. Februar. Patientin hat gestern Abend einmal erbrochen. Hente früh ist sie klar bei Bewusstsein, erst gegen Mittag tritt wieder etwas Unbesinnlichkeit ein. Die Kranke klagt über Kopf- und Brustschmerzen. Die Sklerae sind etwas icterisch verfärbt. Zwei thonfärbige, sehr stinkende Stühle. Die Wunden granuliren nicht, sie sind trocken und reactionslos.

28. Februar. Leichter Icterus am ganzen Körper, Abends lässt die Kranke Stubl und Urin unter sich gehen.

1. März. Früh $6^{1 / 2}$ Uhr Exitus letalis.

Sectionsprotokoll vom 2. März 1895 (Prof. Eppinger).

Körper klein, schwächlich, mager, sehr blass. Hinter dem rechten Ohre befindet sich ein $4 \mathrm{Cm}$. langer, länglichovaler Substanzverlust, zwischen dessen Rảndern die Basis des zum grössten Theile entfernten Warzenfortsatzes zum Vorschein kommt; und der nach hinten und innen $\mathrm{zu}$ bis zum Grunde der hinteren Schädelgrube heranreicht. Im Sinus sigmoideus befindet sich ein Drainrohr. In senkrechter Richtung nach abwärts vom rechten Unterkieferwinkel stösst man auf einen zweiten, $5 \mathrm{Cm}$. langen Substanzverlust mit nahezu vollständig vernarbten Hauträndern, in dessen Tiefe getrennte Bündel eines Halsmuskels sich vorfinden. Zwischen diesen klafft wiederum eine Oeffnung, die gelblich austapezirt erscheint, und in der gleichsfalls ein Drainrohr steckt. Knapp hinter dem linken Trochanter major befindet sich eine $5 \mathrm{Cm}$. lange Schnittwunde durch Hant- und Unterhantzellgewebe hindurch, deren Ränder ziemlich stark geröthet erscheinen. Der linke Unterschenkel ist in der Mitte amputirt.

Schädeldach mässig gross, länglich oval, dünn, porös. Hirnhaut zart, blass durchfenchtet. Hirnsubstanz brüchig, blass. Im rechten Sinus transversus leicht anhaftendes, faserstoffiges Gerinnsel, an das sich an der Umbiegungstelle in den sinus sigmoid. ein bereits gelblich verfärbter, peripher organisirter Thrombus anschliesst. Die übrigen basalen Sinus sind mit theils flussigem, theils geronnenen Blut ausgefüllt.

Unterhautzellgewebe fettreich, Musculatur dünn, blassbraun. Langen beiderseits frei. Herz mässig gross, fettreich, enthält im rechten und linken Vorhof klumpige Faserstoffgerinnsel. Aorta leicht rigid, Herzfleisch blass, brüchig. In der rechten Jugularvene auch nur flüssiges, dunkles Blut. D i eselbe hört plötzlich an der Einmündungsstelle der Thyreoidea sup. auf. Der centrale Hauptstamm, kaum für eine Sonde durchgängig, erscheint in der oben beschriebenen Halswunde. Seine Wandungen sind hier bis zum zugespitzten, blinden Ende bindegewebig verdickt. An der linken Vena jugularis nichts Besonderes. Linke Lunge im Oberlappen lufthaltig, im Unterlappen luftärmer, blutreich, stark durchfeuchtet. Das Gewebe der rechten lunge ist im Ober- und Mittellappen luftleer, starr, grau, brüchig, am Schnitte vom trüben Safte überfliessend, Unterlappen frej. Schleimhaut des Pharynx normal, die des Oesophagus in den unteren Partien mit Soor belegt; entsprechend der Bifurcation der Trachea ein Tractionsdivertikel. Schleimhaut des Larynx und der Tracbea vollständig blass. Aorta thoracica und descendens zartwandig. Lage der Unterleibseingeweide insofern verändert, als der obere Dünndarm an das mesenteriale Blatt des Colon transversum fixirt erseheint. Milz vergrössert, Kapsel gespaunt. Gewebe weich, brüchig, Pulpa reichlich. Linke Niere mässig gross, Kapsel zart,"Gewebe lichtgraubraun, weich, brüchig. Hinter dem Coecum retroperitonealwärts stösst man auf cinen über faustgrossen, mit grünlichem Eiter erfullten Herd, der bis zur rechten Niere heranreicht, die ganz so-beschaffen ist wie die linke. Der Eiterherd sitzt im retroperitonealen Bindegewebe über dem Muscul. iliacus; dieser, sowie der Muscul. psoas sind vollständig unbetheiligt. Nach abwärts reicht der Abscess bis zur Lacuna musculor. Seine Wände sind fetzig. Im Darmkanal gewöhnlicher Inhalt: Die Schleimhaut des Colon durchwegs unverändert. Der Magen enthält nur wenig schleimigen. Inhalt, an seiner hinteren Wand eine ziemlich umfangreiche Narbe eines chronischen Geschwües. Leber ziemlich gross, hurt, brüchig, gelblich gefärbt. Harnblase hochgradig ausgedehnt, Wandung 

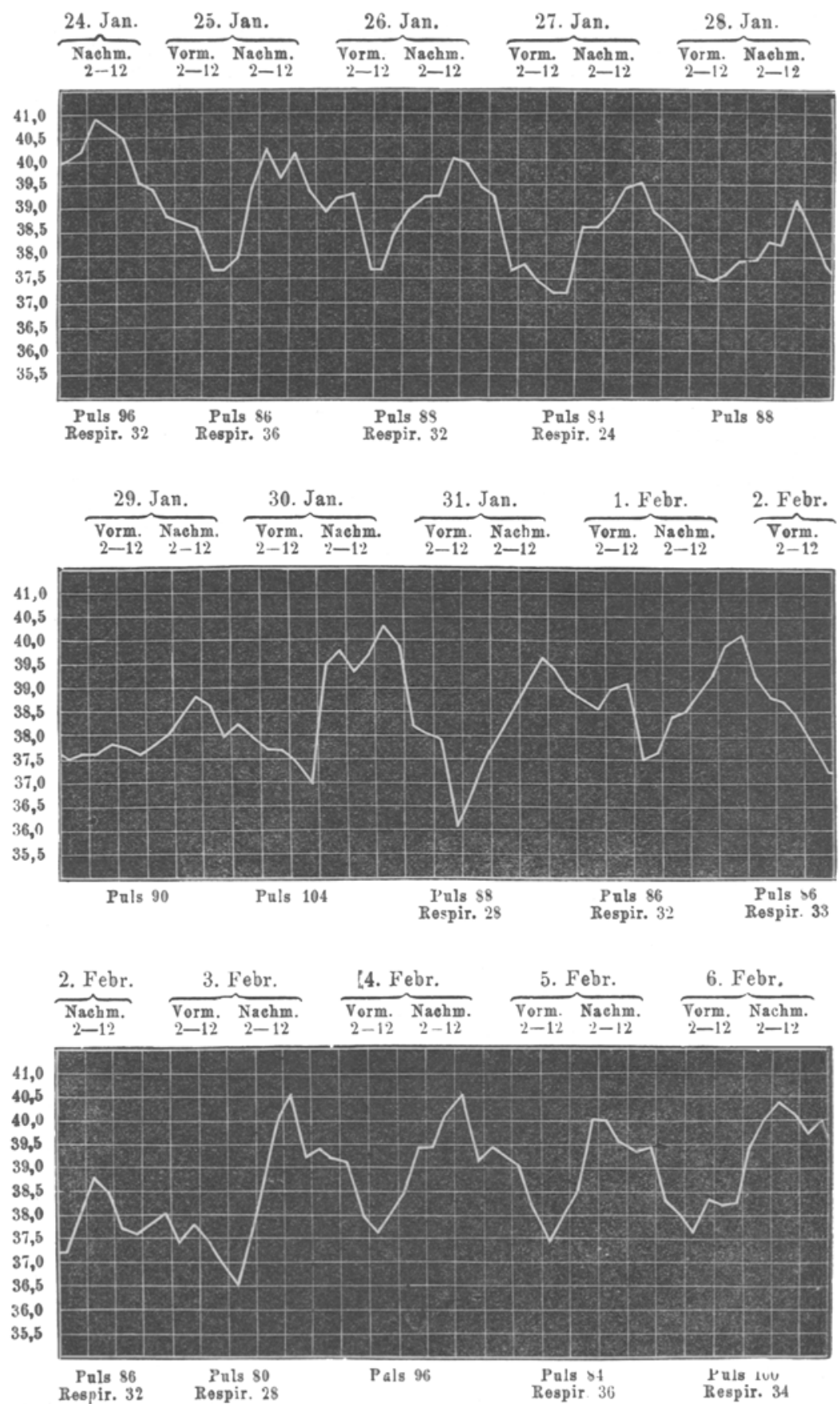

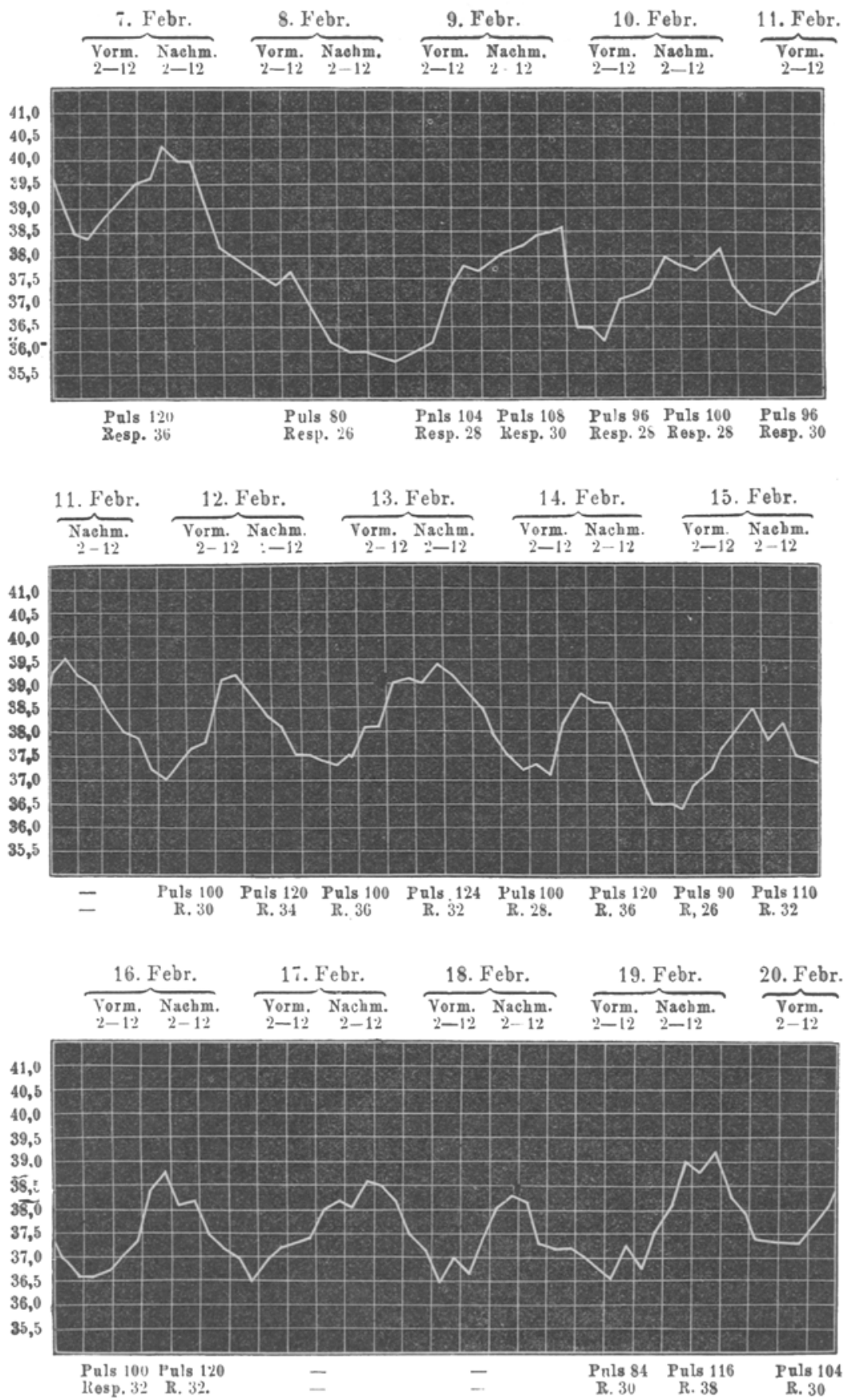


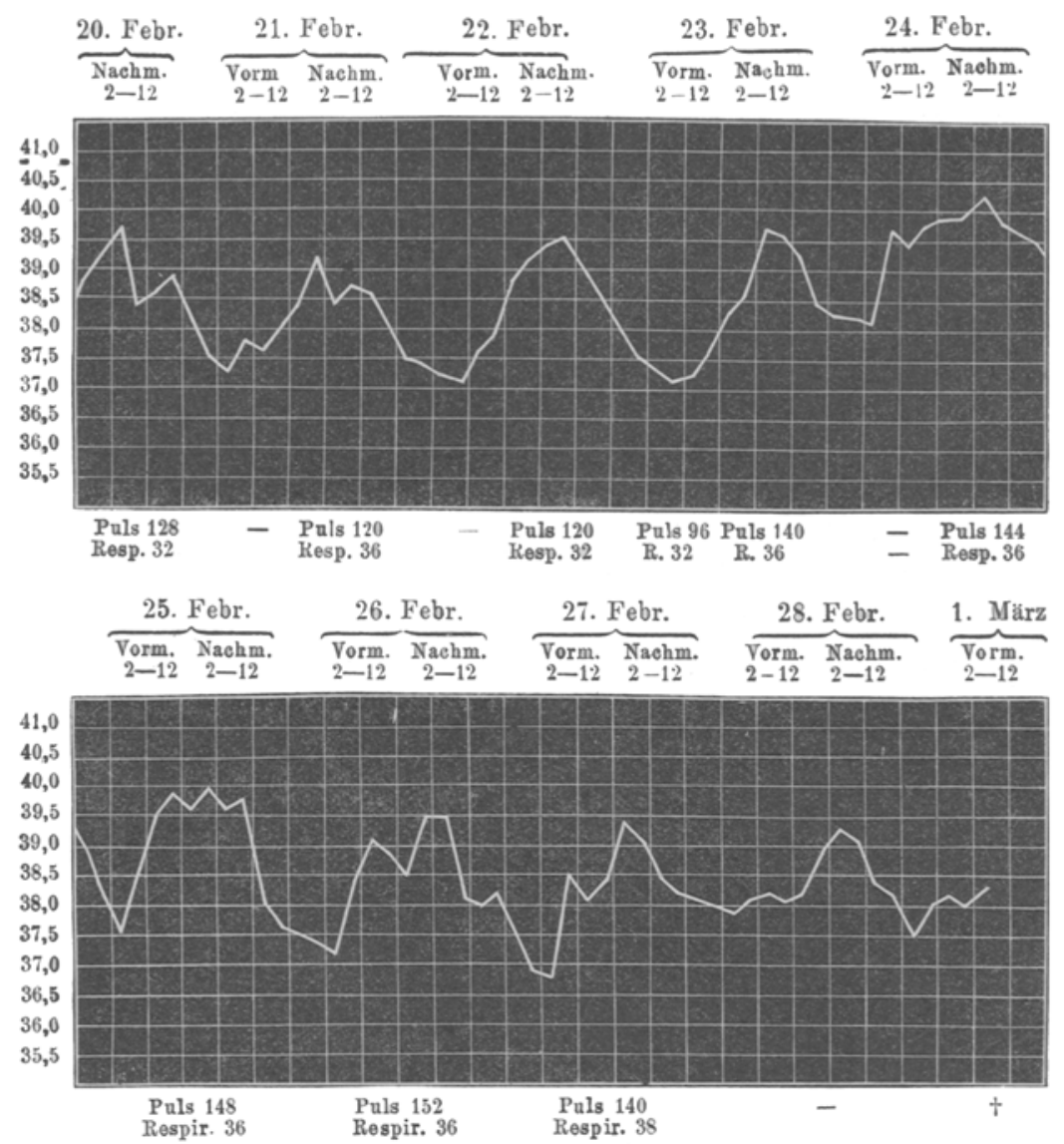

zerreisslich. Schleimhant blass, Vagina lang, weit. Wandungen des Dterus dick, morsch, an der vorderen Wand ein kleines Myom. Rectum und S. Romanum bieten keine Veränderungen dar. Wirbelsäule, Darmbein vollständig frei.

Diagnose: Pneumonia crouposa dextra. Phlebothrombosis organisata sinus sigmoidei dextri et venae jugularis dextrae. Abscessus retrocoecalis et regionis trochanteri sinistri.

Unter ungünstigeren Verhältnissen als den vorliegenden hätte wohl kaum operirt werden können. Schon nach der ersten Untersuchung der Kranken stand für uns die Diagnose einer otogenen Pyämie infolge einer Sinusphlebitis fest. Hierfür sprachen ausser den vorausgegangenen Schïttelfrösten und den sich immer mehr steigernden, unerträglichen, halbseitigen Kopfschmerzen das Erbrechen, die heftigen Besehwerden im Nacken bei Bewegungen, die starke Druckempfindlichkeit längs des Verlaufes der Vena jugularis interna, die hochgradige, beiderseitige Neuritis optica 
und die Metastasen über dem linken Hand- und Hüftgelenk. Als nicht unwesentliche Symptome konnten später gleichfalls noch der charakteristische Fieberverlauf mit den hohen Remissionen, die Milzvergrösserung und die starke Leukocythose angesehen werden. Hätte sich die Kranke sofort bei ihrer Aufnahme ins Spital operiren lassen, und wäre sie nicht ihrer beschränkten Unentschlossenheit gefolgt, wir hätten gewiss die berechtigte Hoffnung hegen können, sie am Leben zu erhalten. Auch der Keim zu dem grossen, retrocoecalen Abscess konnte erst kurz vor dem zu spät gestatteten operativen Eingriff gelegt sein. Obwohl in diesem Falle der natürliche Heilungsvorgang das denkbar Beste dadurch erreichte, dass sich der Körper sowohl gegen das Herz als auch gegen das Schädelinnere zu mit einem festen Schutzwall umgab, und obgleich durch die Freilegung des Sinus sigmoid. und der Vena jugularis interna der primäre Eiterherd vollständig aus dem Organismus ausgeschaltet wurde, erlag doch die durch die lange Dauer der Erkrankung sehr herabgekommene Patientin dem Ansturm einer intercurrenten Pneumonie.

Die operative Freilegung sämmtlicher Mittelohrräume wurde während des verflossenen Zeitabschnittes 20 mal ausgeführt. Hierbei handelte es sich in der Hälfte der Fälle um cariöse Processe allein, die Uebrigen waren mit der Ansammlung cholesteatomatöser Massen im Schläfebein verbunden. Im Allgemeinen streben wir jetzt fast stets einen vollständigen Verschluss der retroauriculären Oeffnung an mit Ausnahme der Fälle, in welchem die Cholesteatommassen den Knochen in grosser Ausdehnung zum Schwund gebracht haben, und eine nur geringe Tendenz zur Verkleinerung der Operationshöhle durch Granulationsbildung besteht. In gleicher Weise suchen wir während der Nachbehandlung durch Aetzungen die Paukenhöhlenmiundung der Ohrtrompete zur Verwachsung za bringen, um spätere Recidive durch Verschleppung von Entzündungserregern rom Nasenrachenraum her zu verhüten.

Ueber die grosse Häufigkeit der Betheiligung der beiden äusseren Gehörknöchelchen an der Mittelohrcaries giebt nachfolgende Tabelle Aufschluss:

Hammer und Ambos cariös ....... 9 mal

Hammer gesund, Ambos cariös .....2=

Beide fehlen ganz .........6 =

Hammer cariös, Ambos fehlt. . . . . . 1 =

Ambos cariös, Hammer fehlt. ......1 =

Hammer gesund, Ambos fehlt ......1 = 
Auch aus dieser kleinen Zusammenstellung geht zur Genüge hervor, dass der Ambos viel leichter der cariösen Zerstörung anheimfällt als der Hammer. In einem Falle wurden neben der vollständigen Einschmelzung des Hammergriffes einige Exostosen am Hammerkopf angetroffen.

Bei 3 Patienten wurde eine tuberculöse Entzlindung des Schläfebeines festgestellt. In einem Falle 1), der bereits in diesem Archive ausfübrlich mitgetheilt wurde, kam es zu einer ausgedehnten Zerstörung des Warzenfortsatzes, des basalen Schuppentheiles, der Felsenbeinpyramide, zu einer theilweisen Thrombose des Sinus petros. sup. und des Sinus sigmoid, sowie zu einer tuberculösen Erkrankung des Keilbeines und des Hinterhauptbeines.

In 2 Fällen waren wir wegen abnormer Vorlagerung des Sinus sigmoid. bis nahe an die hintere knöcherne Gehörgangswand und einmal wegen anormalen Tiefstandes der mittleren Schädelgrube gezwungen, von dem gewöhnlichen Gang der Radicaloperation abzuweichen und das Antrum vom Aditus aus zu eröffnen. Bei 3 Kranken stiessen wir auf einen stark sclerotischen Warzenfortsatz. In 2 Fällen waren in Zerfall begriffene Cholesteatommassen bereits bis zur grau verfärbten Sinuswand vorgedrungen, obne jedoch zu einer Thrombose des grossen Hirnquerblutleiters geführt zu haben. Bei einem 40 jährigen Holzarbeiter $\left.{ }^{2}\right)$ trat nach der Entfernung von reichlichen Granulationen aus der Paukenhöhle eine Lähmung des Nerv. facialis ein, welche zur Zeit bis auf eine geringe Parese des unteren Astes vollständig verschwunden ist. Die pathol. anatom. Veränderungen, welche in diesem Falle angetroffen wurden, sind so interessant, dass sie ihrer Seltenheit wegen etwas eingehender geschildert werden sollen.

Bei der Aufnahme des Patienten befand sich dicht hinter der Ansatzstelle der Ohrmuschel in der Höhe der oberen Gehörgangswand eine ungefähr 20 hellerstückgrosse, nur wenig erbabene, fluctuirende Anschwellung, deren Hautüberzug nicht geröthet war. Nach Durchtrennung der äusseren Weichtheile und der Periostschicht fliesst eine reichliche Menge einer dünnflüssigen, schwarzen, uibelriechenden Flüssigkeit aus dem Warzenfortsatz ab. Nachdem die Beinhaut zurïckgeschoben ist, bemerkt man entsprechend der oben erwähnten Anschwellung einen grösseren Durchbruch im

1) Arch. f. Ohrenheilkunde. Bd. XL. S. 101.

2) Siehe Fall 20. 
Knochen, an den sich nach hinten und unten noch ein kleinerer Defect der Corticalis ansehliesst, weleher von ersterem durch eine $4 \mathrm{Mm}$. breite Spange getrennt ist. Ueber diesen Löchern zeigt sich die Innenfläche des Periostes 'schwärzlich verfärbt. Da die Höhle im Zitzenfortsatz bis zur Spitze herabreicht, wird die ganze laterale Wand des Process. mastoid. entfernt. Der Knochen ist hier hochgradig sclerotisch und von nur wenig stärker blutenden Gefässen durchsetzt. Jetzt blickt man in eine grosse Höhle, die den ganzen Warzentheil umfasst und weit nach hinten und innen reicht. Während in dem vorderen Theile der Höhle die Wandungen mit dicken, aufgelockerten Epidermismassen belegt erscheinen, welche sich durch den Aditus bis in den Kuppelraum fortsetzen, ist der hintere Abschnitt des Hohlraumes mit einer schwarzen, glatten Membran ausgekleidet. In dieser lässt sich die Wand des Sinus sigmoid. von der oberen Umbiegung an nach unten und innen bis nahezu zum Foramen jugulare deutlich übersehen. Sie ist gleichfalls schwärzlich verfärbt, glatt, und fühlt sich beim Betasten mit dem Finger fest an. Im hinteren oberen Theile der Höhle findet sich ein von oben nach hinten unten zu gehender Knochenvorsprung mit einer rundlichen Exostose am Ende vor. Ueber dieser liegt die Dura in der Ausdehnung von $3 \mathrm{Mm}$. im Durchmesser frei zu Tage. Die Paukenhöhle selbst ist von blanrothen Granulationen erfüllt; die vornehmlich von dem hinteren oberen Abschnitt der lateralen Labyrinthwand auszugehen scheinen. Nach $3 \frac{1 / 2}{2}$ Monaten konnte der Patient mit einer grösseren, retroauriculären Oeffnung geheilt entlassen werden. Nach der letzten, uns Ende October 1896 zugegangenen Nachricht ist das Obr trocken geblieben.

Herr Prof. Habermann glaubte, diesen eigenthümlichen pathologischen Befund der Umwandlung eines Cholesteatoms in eine Blut enthaltende Cyste nur so zu erklären za können, dass aus dem wahrscheinlich arrodirt gewesenen Sinus, vielleicht auch nur aus einem grösseren Knochengefäss die Blutung in die dureh das Cholesteatom entstandene Höble erfolgt sei.

Ferner soll hier noch ein Fall von ausgebreiteter Nekrose des Schläfebeins nach Scharlach angeftuhrt werden, bei dem gleichfalls eine vollständige Heilung erzielt wurde. ${ }^{1}$ )

Die kleine, bereits total taube Patientin wurde uns erst 3 Monate nach einer überstandenen schweren Searlatina zugeführt. 
Aus dem linken Ohre hatte sich schon 8 Wochen vorher der cariöse Hammer und Ambos sowie der Steigbügel ausgestossen. Bei ihrer Aufnahme waren die Weichtheile über beiden Warzenfortsätzen hochgradig infiltrirt, und an der typischen Durchbruchstelle fanden sich jederseits zwei tiefe Fisteln vor, welche von einem breiten Granulationswall umgeben waren. Auch in die beiden oberen Halsdreiecke mündeten je zwei nach oben führende Fisteln ein. Der linke Kopfnicker zeigte eine starke, narbige Contractur. Beide äusseren Gehörgänge wurden durch obturirende Polypen vollkommen ausgeftullt. Bei der operativen Freilegung des Krankheitsherdes wurden mebrere grössere Sequester aus den Zitzenfortsätzen entfernt, welche auch Theile der hinteren knöchernen Gehörgangswand mit umfassten. Die entzündlichen Wucherungen waren bereits tief in die Felsenbeinpyramide eingedrungen und hatten die Schnecke zerstört. 8 Wochen später wurde die Kleine geheilt entlassen. Ihr Vater, ein Arzt, schrieb uns Anfang Oetober d. J., dass bis jetzt keine Eiterung aus den Ohren wieder eingetreten sei. Ihr körperliches Befinden sei vorzïglich, geistig jedoch bliebe sie zurtiek. Sie spreche noch verständlich, obwobl ganz in dem ziehenden, Silben verseblingenden Tone wie Taubstumme.

Wäbrend des verflossenen Zeitabschnittes kam auch ein Fall einer gestielten Hypertrophie der Gaumenmandel zur Beobachtung, die zufällig bei einem jungen Manne mit einern Fig. 2. peritonsillären $A$ bscess entdeckt wurde, ohne (1) dass der Kranke selbst eine Vorstellung von ihrem Vorhandensein gehabt hätte. Der ungefähr $3 \mathrm{Cm}$. lange und $2 \mathrm{Cm}$. breite Tumor ging vom unteren Drittel der linken Tonsille ans und stand mit dieser dureh einen ziemlich dünnen, kurzen Stiel in Verbindung. Um diesen herum erhob sich eine grössere Anzahl theils platter, theils länglich gestalteter Auswüichse, die von dem ungleichmässig kugeligen Gebilde durch seichtere, bexiehungsweise tiefere Furchen abgesetzt waren. Der Schleimbautiiberzug war ïberall glatt.

Die mikroskopische Untersucbung ergab die schon makroskopisch gestellte Diagnose einer einfach hypertrophischen Tonsille. Die vielfach gespaltene, zerklüftete Oberfläche der Geschwulst war mit einem mehrschichtigen Pflasterepithel bekleidet, das allenthalben den Tumor überzog. Dieses Pflasterepithel ruhte 
zumeist einer wohlausgebildeten Basalmembran auf, welche an mehreren Stellen von zahlreichen Rundzellen durchsetzt erschien. Unter diesem schmalen Bindegewebsstreifen stösst man auf ein diffus angeordnetes, dichtes lymphatisches Gewebe mit einem äusserst zarten Reticulum, welches allmählich einem zellärmeren, lockeren Stützgewebe Platz macht. In diesem verlaufen zahlreiche Gefässe, die dicht mit Blat vollgestopft sind und sich fächerförmig zur Oberfläche hin ausbreiten.

Bei dem so mannigfachen Wechsel in der Configuration der Tonsillen darf uns die Umbildung eines der zahlreichen Lappen derselben $z \mathfrak{u}$ einer gestielten Hypertrophie nicht tberrasehen. Ferner kommt es nicht gar selten zur Entwicklung einer ïberzähligen Mandel, oder die Tonsille selbst kann so locker an ihrer gewöhnlichen Anheftungsstelle befestigt sein, dass sie den Eindruck eines wahren Polypen hervorruft. 


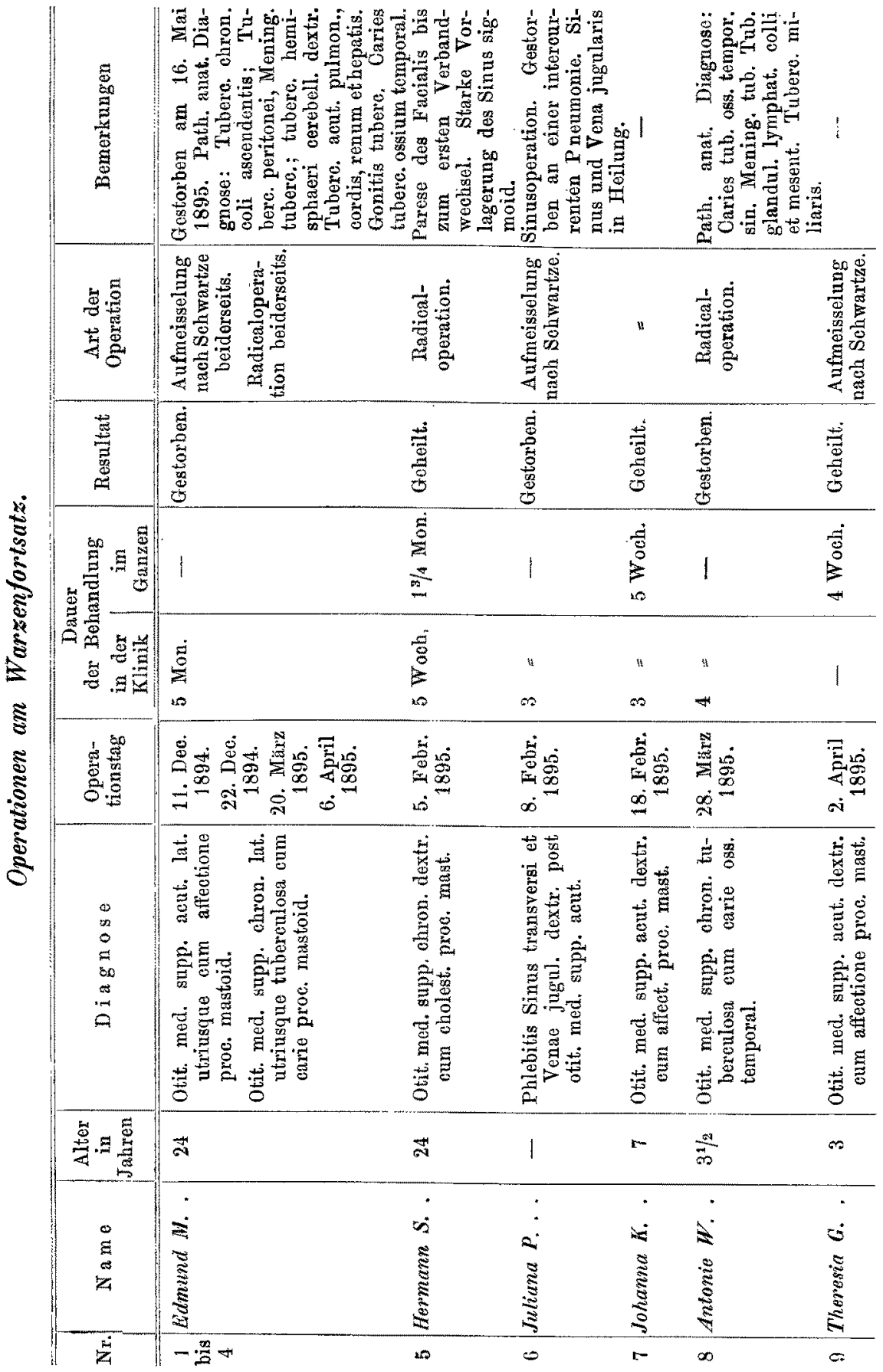




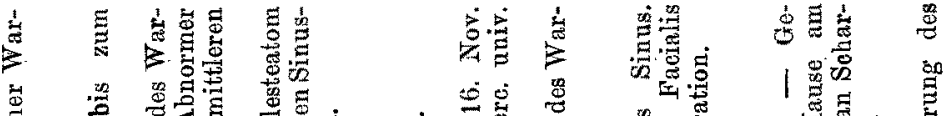

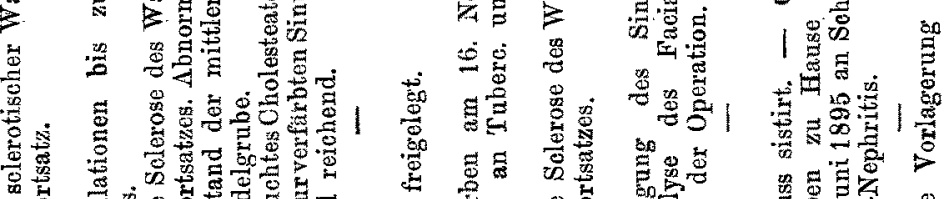
w

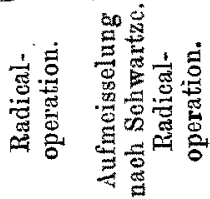
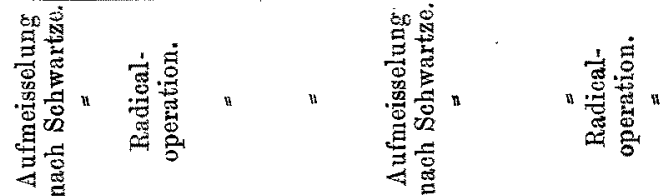

\begin{tabular}{|c|c|c|c|c|c|c|c|c|c|c|c|c|c|}
\hline סמ" & 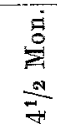 & $\begin{array}{l}5 \\
0 \\
0\end{array}$ & 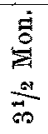 & 1 & 1 & 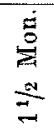 & 1 & $\underbrace{3}_{0}$ & 1 & $\begin{array}{l}\dot{3} \\
0 \\
0\end{array}$ & 1 & 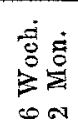 & 1 \\
\hline 1 & $\underset{8}{\stackrel{B}{0}}$ & 1 & 1 & 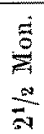 & $\frac{5}{8}$ & 1 & $\sum_{\substack{0 \\
: 1}}$ & 1 & $\frac{\sum_{0}^{3}}{\frac{j}{2}}$ & 1 & 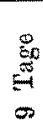 & $\begin{array}{l}0 \frac{8}{0} \\
\underbrace{}_{0}\end{array}$ & 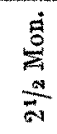 \\
\hline
\end{tabular}

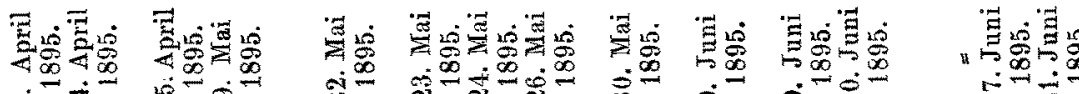

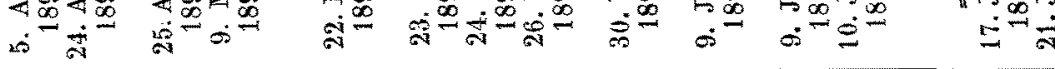

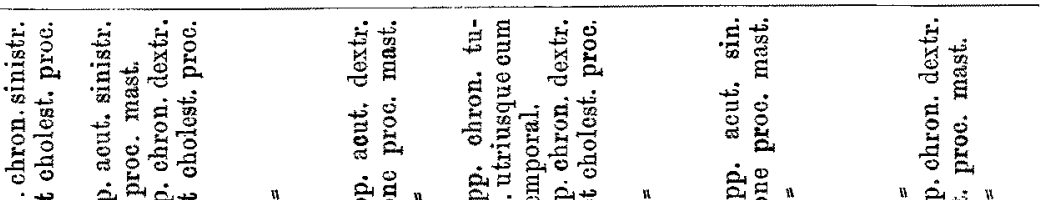

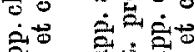

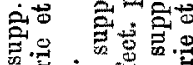

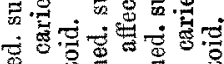

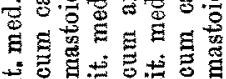

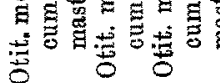

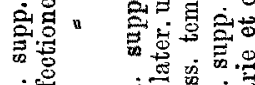

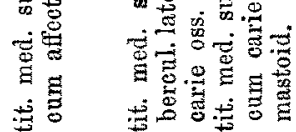

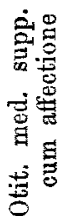 $\approx \quad \Rightarrow \quad \frac{9}{10}$ สำษ ส

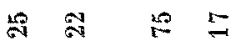

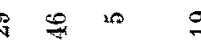

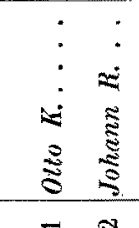

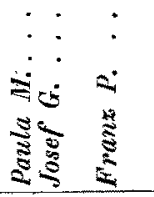

의 $\cong$

$25 \frac{20}{2}$

8

สํี 
118 VII. BARNICK, Bericht aus Prof. Habermana's Klinik u. s. w,

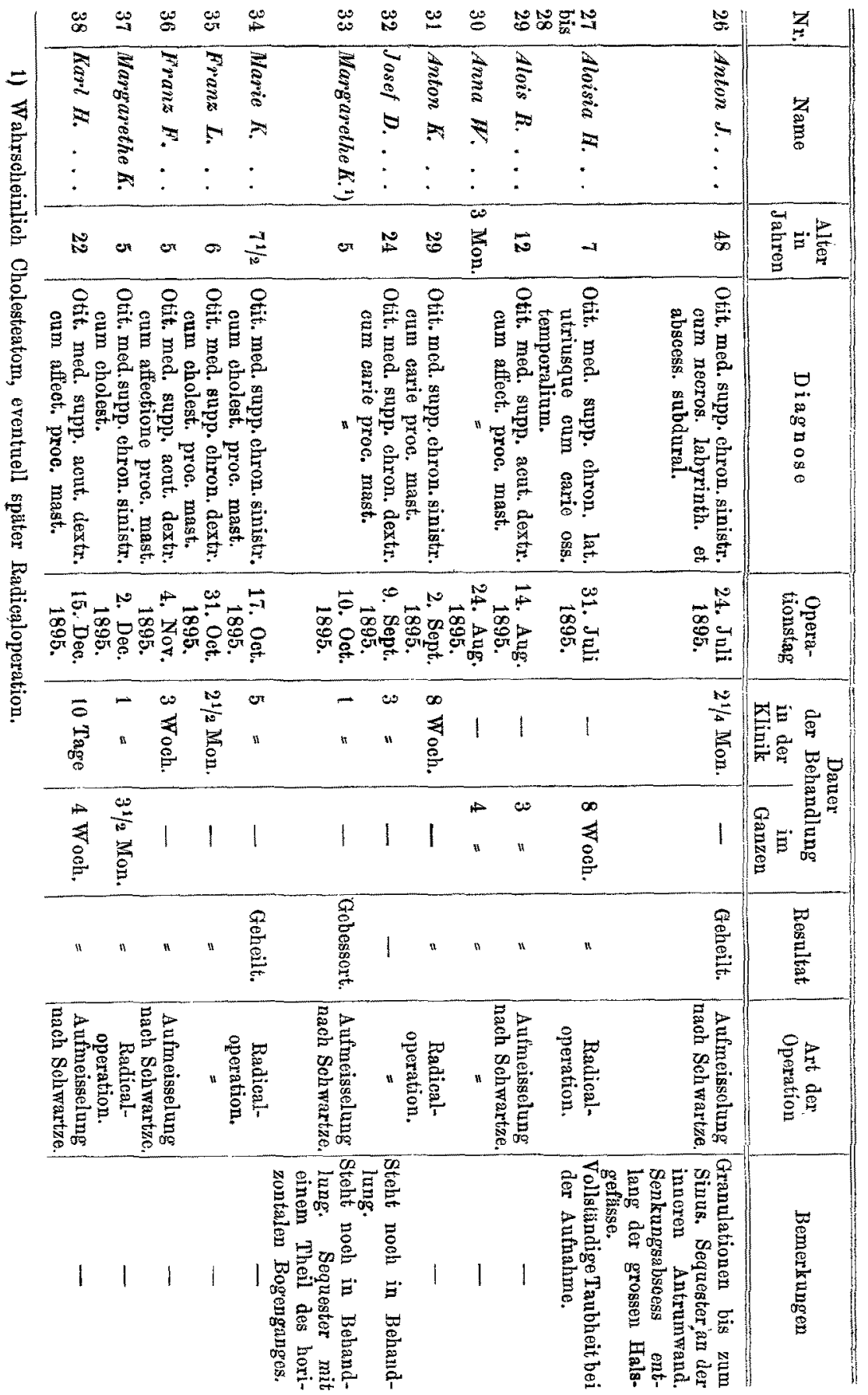

